Original Research Paper

\title{
EFEKTIVIFAS TERAPI KOMBINASI PEMBERIAN SEDUHAN KEMBANG TELANG/BUTTERFLY PEA (CLITTORIA TERNATEA) DAN LAMAZE EXERCISE TERHADAP PENURUNAN NYERI HAID (DISMENOROE) PADA REMAJA PUTRI
}

\author{
Julina Br Sembiring ${ }^{1 *}$, Dalimawaty Kadir $^{2}$, Rahmawati Tarigan $^{3}$ \\ ${ }^{1,3}$ Institut Kesehatan Helvetia \\ ${ }^{2}$ STKIP Asy-Syafi'iyah Internasional Medan
}

Email Corresponding*:

azkatepu@gmail.com

Page : 44-51

Kata Kunci : Nyeri haid, Terapi Kombinasi, Remaja Putri

Keywords:
Combination
Women

Published by:

Tadulako University,

Managed by Faculty of Medicine.

Email: healthytadulako@gmail.com

Phone (WA): +6285242303103

Address:

Jalan Soekarno Hatta Km. 9. City of

Palu, Central Sulawesi, Indonesia
Dismenore dapat menimbulkan dampak bagi kegiatan atau aktivitas remaja putri. Dismenore membuat remaja putri tidak bisa beraktivitas secara normal dan memerlukan resep obat. Keadaan tersebut menyebabkan menurunnya kualitas hidup remaja putri. Tujuan dari penelitian ini adalah untuk mengetahui Efektivitas kombinasi Pemberian Seduhan Kembang Telang/Butterfly Pea (Clittoria Ternatea) dan Lamaze Exercise terhadap penurunan intensitas nyeri haid pada remaja putri di Desa Lau Mulgap . Penelitian ini menggunakan desain penelitian Quasi Eksperimen dengan one group pretest-posttest design, melibatkan 43 remaja putri. Teknik sampling menggunakan purposive sampling, yaitu sampel harus memenuhi kriteria inklusi dan eksklusi yang telah ditentukan oleh peneliti. Hasil uji paired t-test diperoleh nilai $\mathrm{p}=0.000(<0.05)$, menunjukkan Efektivitas kombinasi Pemberian Seduhan Kembang Telang/Butterfly Pea (Clittoria Ternatea) dan Lamaze Exercise efektif dalam menurunkan intensitas nyeri haid. Hasil penelitian perbedaan intensitas nyeri haid sebelum dan sesudah intervensi, maka dilakukan uji statistik Paired t-test . Berdasarkan hasil uji statistik diperoleh nilai rata-rata intensitas nyeri haid saat Pre intervensi adalah 2.37 dengan SD 0.926, sedangkan saat dilakukan Post intervensi, nilai rata-rata nyeri haid menjadi 1.950 dengan SD 0.950. Secara statistik nilai rata-rata perbedaan antara pre intervensi dan post intervensi adalah 0.419 dengan nilai $\mathrm{p}$ value yaitu 0.013 , maka dapat disimpulkan bahwa nilai $\mathrm{P}<0.05$. Nilai tersebut menunjukkan adanya perbedaan yang signifikan antara ratarata nyeri haid sebelum dan sesudah dilakukan terapi kombinasi. Dengan demikian dapat disimpulkan bahwa nyeri haid menurun setelah dilakukan terapi kombinasi Pemberian Seduhan Kembang Telang/Butterfly Pea (Clittoria Ternatea) dan Lamaze Exercise terhadap penurunan intensitas nyeri haid.

ABSTRACT
Dysmenorrhea can have an impact on the activities or activities of young women.
Dysmenorrhea makes young women unable to carry out normal activities and
require prescription drugs. This situation causes a decrease in the quality of life of
young women. The purpose of this study was to determine the effectiveness of the
combination of giving infusion of Kembang Telang/Butterfly Pea (Clittoria
Ternatea) and Lamaze Exercise to decrease the intensity of menstrual pain in
adolescent girls in Lau Mulgap Village. This study used a quasi-experimental
research design with one group pretest-posttest design, involving 43 young women.
The sampling technique used purposive sampling, namely the sample must meet the
inclusion and exclusion criteria that have been determined by the researcher. The
results of the paired t-test were obtained with a value of p = 0.000 (<0.05),
indicating the effectiveness of the combination of Giving Kembang Telang/Butterfly
Pea (Clittoria Ternatea) and Lamaze Exercises combination effective in reducing
the intensity of menstrual pain. The results of the study of differences in the intensity
of menstrual pain before and after the intervention, then the Paired t-test statistical
test was carried out. Based on the results of statistical tests, the average value of
menstrual pain intensity during pre-intervention was 2.37 with an SD of 0.926,
while at post-intervention, the average value of menstrual pain was 1.950 with an


SD of 0.950. Statistically, the average difference between pre-intervention and postintervention was 0.419 with a p-value of 0.013 , so it can be concluded that the Pvalue $<0.05$. This value indicates a significant difference between the average menstrual pain before and after combination therapy. Thus, it can be concluded that menstrual pain decreased after a combination therapy of giving infusion of Kembang Telang/Butterfly Pea (Clittoria Ternatea) and Lamaze Exercise was done to decrease the intensity of menstrual pain.

\section{PENDAHULUAN}

Menstruasi merupakan perdarahan periodik sebagai bagian integral dari fungsional biologis wanita sepanjang siklus kehidupannya. Pada remaja, biasanya pertama kali mengalami menstruasi pada usia 12-16 tahun $^{1}$.

Siklus menstruasi normal terjadi setiap 22-35 hari, dengan lamanya menstruasi selama 2-7 hari. Hormon-hormon yang memengaruhi terjadinya haid pada seorang wanita yaitu FSH, LH, estrogen serta progesteron ${ }^{2}$. Dismenore adalah rasa nyeri yang muncul sewaktu menjelang haid atau pada saat Menstruasi. Gejalanya di tandai rasa mulas atau sakit pada perut bagian bawah sampai ke pinggang dan paha ${ }^{3}$.

Gejala klinis dismenore primer berupa nyeri kram mulai 24 jam sebelum menstruasi dan mungkin bertahan selama 24 sampai 36 jam, walaupun nyeri berat hanya berlangsung selama 24 jam pertama. Nyeri dirasakan pada abdomen bawah tetapi dapat menjalar ke punggung atau permukaan paha ${ }^{4}$.

Otot dinding rahim pada wanita setiap saat akan mengalami kontraksi yang sangat lembut, bahkan saking lembutnya kontraksi tersebut sama sekali tidak dirasa. Tapi beda halnya ketika masa menstruasi tiba, pergerakan kontraksi akan semakin kencang yang disebabkan adanya proses menggugurkan pembuluh darah yang menebal pada dinding rahim, sehingga menimbulkan rasa nyeri ${ }^{3}$.

Produksi prostaglandin yang berlebihan menimbulkan rasa nyeri, sedangkan kontraksi uterus yang terus menerus menyebabkan suplai darah ke uterus terhenti dan terjadi dismenore ${ }^{5}$.

Skala Penilaian Nyeri Numeral Rating Scale (NRS) yaitu:0 (tidak nyeri): Tidak ada nyeri yang dirasakan, 1-3 (nyeri ringan) : Nyeri dirasakan tetapi tidak mengganggu kegiatan yang dilakukan, dapat berkomunikasi dengan baik, dapat mengikuti perintah dengan baik, dapat menunjukkan lokasi nyeri dengan tepat dan mendeskripsikannya, 4-6 (nyeri sedang): Nyeri menyebabkan kegiatan yang dilakukan jadi lambat terselesaikan, masih dapat mengikuti perintah dengan baik, dapat menunjukkan lokasi nyeri dengan tepat dan dapatmendeskripsikannya, mendesis dan menyeringai, 7-9 (nyeri berat terkontrol): Nyeri menyebabkan tidak dapat melakukan kegiatan seharihari, masih responsif terhadap tindakan manual, menunjukkan lokasi nyeri dengan tepat namun tidak dapat mendeskripsikannya, tidak dapat mengikuti perintah, klien tidak dapat diatur untuk alih posisi, napas panjang, dan mengalihkan perhatian, 10 (nyeri berat tidak tertahankan: Tidak mampu berkomunikasi dengan baik, tidak dapat menunjukkan lokasi nyeri, berteriak dan histeris, tidak dapat mengikuti perintah, menarik apa saja yang tergapai ${ }^{6}$.

Dismenore yang sering terjadi pada remaja putri umumnya adalah dismenore primer ${ }^{5}$. Dismenore disebabkan oleh faktor psikologis dan endokrin. Remaja putri secara emosional tidak stabil, sehingga dengan sedikit rangsangan nyeri maka ia akan merasa kesakitan. Dismenore juga dihubungkan dengan kontraksi uterus yang tidak baik. Hal ini 
erat kaitannya dengan pengaruh hormon. Produksi prostaglandin yang meningkat akan menyebabkan kontraksi uterus yang tidak terkoordinasi sehingga menimbulkan nyeri. ${ }^{7}$

Gejala dari nyeri haid primer berupa rasa nyeri di perut bagian bawah, menjalar ke daerah pinggang dan paha. Kadang-kadang disertai mual, muntah, diare, sakit kepala dan emosi yang labil. Nyeri timbul sebelum haid dan berangsur hilang setelah darah haid keluar. Gejala klinis dismenore primer berupa nyeri kram mulai 24 jam sebelum menstruasi dan mungkin bertahan selama 24 sampai 36 jam, walaupun nyeri berat hanya berlangsung selama 24 jam pertama. Nyeri dirasakan pada abdomen bawah tetapi dapat menjalar ke punggung atau permukaan paha. Pada kasus berat, nyeri dapat disertai muntah dan diare. Disamping itu remaja yang mengalami dismenore primer juga terlihat gejala-gejala umum seperti rasa tidak enak badan, lelah, mual, muntah, diare, nyeri punggung bawah, sakit kepala, kadang-kadang dapat juga disertai vertigo, perasaan cemas, gelisah, hingga jatuh pingsan $^{8}$

Dismenore sangat berdampak pada remaja putri, hal ini menyebabkan terganggunya aktivitas sehari-hari. Remaja yang mengalami dismenore pada saat menstruasi membatasi aktivitas harian mereka khususnya aktivitas belajar di sekolah. Aktivitas belajar merupakan prinsip atau azas yang sangat penting di dalam interaksi belajar yang bukan hanya melibatkan aktivitas fisik tetapi juga mental. ${ }^{4}$

Penatalaksanaan dismenore dapat dilakukan dengan terapi non farmakologi, yaitu Pemberian seduhan Kembang Telang/Butterfly Pea (Clitoria ternatea). Bunga telang atau kembang telang (Clitoria ternatea) telah dipercaya sejak zaman dahulu sebagai obat herbal, untuk berbagai macam penyakit seperti obat mata, antidiuretik, batuk, melancarkan haid dan yang paling penarik adalah sebagai anti stres ${ }^{9}$.
Bunga Telang mengandung antosianin dan warnanya bisa berubah sesuai PH. Kembang Telang atau Butterfly Pea memiliki segudang manfaat baik bagi kesehatan dan bagus untuk detoksivikasi dan yang terpenting adalah untuk kesehatan seksual wanita yang mengalami gangguan haid. Bunga Telang terkenal bisa melancarkan siklus haid dan meningkatkan kesuburan rahim ${ }^{10}$.

Salah satu manfaat Bunga Telang adalah untuk memperlancar haid, yaitu dengan cara merebus beberapa bunga dari bunga teleng. Kemudian diminum setelah sebelumnya di campur dengan gula supaya tidak terlalu pahit. Maka haid pun menjadi lancar ${ }^{11}$.

Penanggulangan nyeri non farmakologis, yang salah satunya dengan menggunakan teknik relaksasi bernafas sesuai dengan Metode Dr. Lamaze yang mendapat gagasan dari Dr. Greatley Dick Read bahwa nyeri pada saat melahirkan terjadi lantaran rasa takut yang berlebihan. Rasa nyeri itu dapat diredam bahkan dihilangkan dengan latihan relaksasi selama proses kehamilan untuk mengatasi secara aktif rasa sakit akibat persalinan dan menghindari atau mengurangi penggunaan obat. Sehingga ibu dapat lebih mudah dan berkurang cemasnya saat menghadapi proses persalinan ${ }^{12}$.

Lamaze exercise merupakan teknik relaksasi nafas yang dapat dijadikan sebagai salah satu kompetensi nonfarmakologis dalam upaya menurunkan nyeri menstruasi pada remaja. Kelebihan dari Lamaze exercise dibanding terapi non farmakologi lain adalah mudah diaplikasikan sewaktu-waktu saat nyeri menstruasi timbul ${ }^{13}$.

Lamaze exercise yang dilakukan pada remaja putri saat nyeri menstruasi akan memberikan persepsi positif yang kemudian diterima oleh korteks cerebri. Metode Lamaze dilakukan dengan cara mengatur pernapasan untuk mengurangi rasa sakit. Pengaturan pernapasan dilakukan dengan berbagai macam pola, seperti menghirup napas dalam-dalam 
selama lima detik dan keluarkan selama lima detik, dan ulangi terus menerus. Pola lainnya, yaitu dengan mengambil dua napas pendek dan kemudian mengeluarkannya. Selain mengajarkan teknik pernapasan, Lamaze juga mengajarkan teknik relaksasi sentuhan untuk meminimalkan rasa sakit ${ }^{13}$.

\section{BAHAN DAN CARA}

Desain penelitian yang digunakan dalam penelitian ini adalah quasi experimen. Rancangan penelitian yang digunakan one group pretest-posttest design. Sebelum dilakukan intervensi, diawali dengan pengukuran intensitas nyeri (pre-test). Setelah diberi intervensi yaitu pemberian seduhan Kembang Telang dan Lamaze exercise, diakhiri dengan pengukuran intensitas nyeri kembali (post-test).

Populasi dalam penelitian ini adalah remaja putri yang mengalami nyeri haid (dismenore) sebanyak 43 orang di Desa Lau Mulgab. Teknik sampling menggunakan purposive sampling. Penelitian ini dilakukan di Desa Lau Mulgap Kecamatan Selesai Kabupaten Langkat. Instrumen penelitian ini menggunakan kuesioner data demografi dan lembar observasi skala nyeri menggunakan alat ukur skala nyeri numerik (NRS). Numerical Rating Scale (NRS) yaitu alat pendeskripsi dengan skala 0-10.

Pengumpulan data dilakukan terlebih dahulu dengan mengajukan permohonan izin pelaksanaan penelitian kepada institusi. Setelah peneliti mendapat rekomendasi pelaksanaan penelitian maka peneliti melaksanakan pengumpulan data. Kemudian peneliti mensosialisasikan kegiatan yang dilakukan. Selanjutnya diberikan penjelasan tujuan dan prosedur penelitian serta meminta persetujuan dari calon responden yang bersedia berpartisipasi menjadi sampel penelitian.

Peneliti juga menganjurkan seluruh responden untuk tidak melakukan penangangan mengurangi nyeri seperti minum air hangat, mengoleskan minyak kayu putih atau meakukan kompres pada perut. Setelah calon responden menyatakan bersedia mengikuti prosedur penelitian, maka responden diminta menandatangani informed consent yang telah disiapkan peneliti. Peneliti telah menyediakan bunga telang kering yang akan diseduh dan juga mengajarkan teknik Lamaze Exercise pada responden agar dilakukan dengan benar.

Kemudian peneliti memberian nomor telepon, jika responden mengalami nyeri haid dapat langsung memberitahu peneliti ketika mulai merasakan dismenore. Peneliti memberikan lembar observasi pengukuran skala nyeri numerik untuk memilih salah satu angka dari skala tersebut sesuai dengan tingkat nyeri yang dirasakan sebelum diberi intervensi. Kemudian responden diberikan seduhan Kembang Telang yang diseduh dengan 3 kembang telang kering dikonsumsi 3 gelas sehari dan dikonsumsi selama 1 hari sebelum perkiraan haid dan sampai datang haid.

Kemudian melakukan teknik Lamaze Exercise selama menstruasi serta Setelah meminum seduhan Kembang Telang pada hari pertama dismenore dan melakukan Lamaze Exercise, peneliti meminta responden untuk mengisi kembali lembar observasi skala nyeri numerik. Analisa univariat digunakan untuk menjelaskan atau mendeskripsikan karakteristik responden. Analisis bivariat digunakan untuk mengetahui perbedaan intensitas nyeri haid sebelum dan sesudah dilakukan terapi kombinasi.

Dalam menganalisa data secara bivariat, pengujian data dilakukan dengan uji statistik paired t-test yakni membandingkan skala intensitas nyeri haid (dismenore) sebelum dan sesudah diberikan terapi kombinasi. variabel intensitas nyeri haid menunjukkan bahwa variabel intensitas nyeri haid terdapat distribusi skor yang normal $(\mathrm{p}>0.00)$. 
HASIL

Tabel 1. Distribusi frekuensi dan persentase berdasarkan data demografi responden $(n=43)$

\begin{tabular}{|c|c|c|}
\hline \multirow[t]{2}{*}{ Umur } & \multicolumn{2}{|c|}{ Kelompok } \\
\hline & $\mathbf{f}$ & $\%$ \\
\hline Remaja Awal (12-14) & 21 & 48,8 \\
\hline Remaja Madya (15-18) & 22 & 51,2 \\
\hline Total & 43 & 100 \\
\hline Siklus Menstruasi & \multicolumn{2}{|c|}{ Kelompok } \\
\hline 27 Hari & 5 & 11,6 \\
\hline 28 Hari & 14 & 32,6 \\
\hline 29 Hari & 9 & 20,9 \\
\hline 30 Hari & 15 & 34,9 \\
\hline Total & 43 & 100 \\
\hline
\end{tabular}

Sumber: Data Primer, 2021

Tabel 2. Intensitas nyeri haid sebelum dan sesudah intervensi $(n=43)$

\begin{tabular}{lcccc}
\hline \multirow{2}{*}{ Intensitas Nyeri Dismenore } & \multicolumn{2}{c}{ Sebelum Intervensi } & \multicolumn{2}{c}{ Setelah Intervensi } \\
\cline { 2 - 5 } & $f$ & $\%$ & $f$ & $\%$ \\
\hline Tidak nyeri & 2 & 4,7 & 2 & 4,7 \\
Nyeri ringan & 4 & 9,3 & 13 & 30,2 \\
Nyeri sedang & 16 & 37,2 & 14 & 32,6 \\
Nyeri berat terkontrol & 17 & 39,5 & 13 & 30,2 \\
Nyeri berat tidak terkontrol & 4 & 9,3 & 1 & 2,3 \\
Total & $\mathbf{4 3}$ & $\mathbf{1 0 0}$ & $\mathbf{4 3}$ & $\mathbf{1 0 0}$ \\
\hline
\end{tabular}

Tabel 3. Perbedaan intensitas nyeri haid sebelum dan sesudah intervensi dengan uji statistik Paired t-test

\begin{tabular}{|c|c|c|c|c|c|c|}
\hline \multirow[b]{2}{*}{ Variabel } & \multicolumn{2}{|c|}{ Pre-test } & \multicolumn{2}{|c|}{ Post-test } & \multirow{2}{*}{ P-Value } & \multirow{2}{*}{ Mean difference } \\
\hline & $\overline{\text { Mean }}$ & SD & Mean & SD & & \\
\hline Intensitas nyeri haid & 2.37 & 0.926 & 1.95 & 0,950 & 0.013 & 0,419 \\
\hline
\end{tabular}

\section{PEMBAHASAN}

\section{Bunga Telang}

Hasil uji statistik diperoleh nilai ratarata intensitas nyeri haid saat Pre intervensi adalah 2.37 dengan SD 0.926, sedangkan saat dilakukan Post intervensi, nilai rata-rata nyeri haid menjadi 1.950 dengan SD 0.950. Secara statistik nilai rata-rata perbedaan antara pre intervensi dan post intervensi adalah 0.419 dengan nilai $\mathrm{p}$ value yaitu 0.013 , maka dapat disimpulkan bahwa nilai $\mathrm{P}<0.05$. Nilai tersebut menunjukkan adanya perbedaan yang signifikan antara rata-rata nyeri haid sebelum dan sesudah dilakukan terapi kombinasi. Dengan demikian dapat disimpulkanbahwa nyeri haid menurun setelah dilakukan terapi kombinasi Pemberian Seduhan Kembang Telang/Butterfly Pea (Clittoria Ternatea) dan Lamaze Exercise terhadap penurunan intensitas nyeri haid pada remaja putri.

Bunga Telang mengandung saponin, tanin, triterpenoid, plobatanin, flavonoid, fenol, steroid, alkaloid, antosianin, antrakuinon, minyak esensial bagi sebagian 
wanita terkadang mengalami masalah menstruasi yang tidak lancar. Bunga telang ini dapat digunakan untuk memperlancar siklus haid. Banyak hal yang menyebabkan tidak teraturnya masalah menstruasi, namun dengan mengkonsumsi bunga telang, hal tersebut dapat diatasi. Selain itu, menurut penelitian Journal of Traditional and Complimentary Medicine, bunga cantik ini juga mampu membantu mengatasi beberapa masalah reproduksi pada perempuan selain menstruasi yang tidak teratur. misalnya seperti keputihan yang tidak normal ${ }^{14}$.

Potensi farmakologi bunga telang anta lain adalah sebagai antioksidan, antibakteri, anti inflamasi dan analgesik, antiparasit dan antisida, antidiabetes, antikanker, antihistamin, immunomodulator, dan potensi berperan dalam susunan syaraf pusat, Central Nervous System (CNS).

Asumsi peneliti dari penelitian ini terapi kombinasi Pemberian Seduhan Kembang Telang/Butterfly Pea (Clittoria Ternatea) dan Lamaze Exercise efekti dalam menurunan Intensitas nyeri haid pada remaja putri karena dari responden sebelum dilakuan intervensi ada yang mengeluh nyeri berat tidak terkontrol sebanyak 4 orang (9,3\%) tetapi setelah responden melakukan terapi kombinasi dan setelah dilakukan intervensi didapatkan hanya 1 orang $(2,3 \%)$ yang mengalami nyeri berat tidak terkontrol. Sebagian besar responden tetap mengalami nyeri sedang. Sebagian responden juga mengalami nyeri berat terkontrol. Ini disebabkan responden tidak tahu cara untuk mengatasi nyeri haid. Kelebihan dari Pemberian Seduhan Kembang Telang/Butterfly Pea (Clittoria Ternatea) dan Lamaze Exercise dibanding terapi non farmakologi lain adalah bebas dari efek samping dan mudah diaplikasikan sewaktu-waktu saat nyeri menstruasi timbul. Jadi terapi kombinasi tersebut bisa atau dapat digunakan untuk menurunkan tingkat nyeri menstruasi.

\section{Lamaze Exercise}

Selain itu banyak dikembangkan cara non-farmakologis untuk mengatasi nyeri. Salah satu penelitian dilakukan oleh Lamaze tentang analgesik psikologis dimana ibu diberikan persiapan psikologis pada saat kehamilan dengan cara pemberian sugesti dan motivasi. Salah satu metode tersebut adalah teknik Relaksasi yaitu sebuah teknik relaksasi yang bertujuan untuk mengurangi stress dan meningkatkan perasaan tenang dan damai serta merupakan obat penenang untuk situasi yang sulit dalam kehidupan. Imajinasi terbimbing merupakan salah satu jenis dari teknik relaksasi sehingga manfaat dari teknik ini pada umumnya sama dengan manfaat dari teknik relaksasi yang lain ${ }^{12}$.

Pemberian teknik relaksasi bertujuan untuk memberi efek penurunan nyeri yang efektif, dengan mengalihkan perhatian klien sehingga klien berfokus pada stimulus dan mengabaikan sensasi nyeri, yang pada akhirnya dapat menurunkan persepsi nyeri. Nyeri menstruasi dapat diatasi dengan manajemennyeri yaitu suatu tindakan atau strategi khusus untuk menghilangkan nyeri, antara lain dengan tindakan farmakologi (asam mefenamat) dan non farmakologi. Lamaze exercise merupakan salah satu gerakan latihan relaksasi nafas yang dapat digunakan untuk menurunkan nyeri menstruasi. Nyeri menstruasi yang dialami oleh sebagian besar responden dapat menurun mungkin dikarenakan teknik ini mudah untuk dilakukan tanpa ada efek samping ${ }^{13}$.

Asumsi peneliti menyatakan bahwa penurunan skala nyeri menstruasi sebanyak 3-4 poin hampir dialami oleh sebagian besar responden. Strategi untuk mengatasi rasa nyeri antara lain memusatkan perhatian pada titik perhatian tertentu, sehingga jalur saraf terisi oleh stimulus lain dan tidak dapat memberi respon terhadap stimulus nyeri. Penurunan nyeri menstruasi yang dialami oleh sebagian besar responden dikarenakan responden dapat 
mengikuti teknik Lamaze exercise dengan baik dan benar, mereka melakukan teknik ini dengan fokus.

\section{KESIMPULAN DAN SARAN}

Mayoritas responden yang mengalami dismenore adalah berusia 15-18 tahun sebanyak 22 orang $(51.2 \%)$, seluruh responden dalam penelitian ini memiliki siklus haid normal (22- 35 hari) dengan siklus haid mayoritas 28 hari sebanyak 14 orang (32.6\%).

Hasil uji statistik diperoleh nilai rata-rata intensitas nyeri haid saat Pre intervensi adalah 2.37 dengan SD 0.926, sedangkan saat dilakukan Post intervensi, nilai rata-rata nyeri haid menjadi 1.95 dengan SD 0.950. Secara statistik nilai rata-rata perbedaan antara pre intervensi dan post intervensi adalah 0.419 Hasil uji statistik diperoleh nilai $\mathrm{p}=0,013$, maka dapat disimpulkan bahwa Pemberian Seduhan Kembang Telang/Butterfly Pea (Clittoria Ternatea) dan Lamaze Exercise efektif dalam menurunkan intensitas nyeri haid.

Diharapan penelitian ini sebagai sumber informasi dan pengetahuan bagi pendidikan kebidanan untuk mengembangkan tindakan mandiri bidan terapi kombinasi (Pemberian Seduhan Kembang Telang/Butterfly Pea (Clittoria Ternatea) dan Lamaze Exercise) dalam praktek kebidanan, masyaakat dapat mengimplementasikan terapi komplementer lamaze Exercise untuk menurunkan intensitas nyeri haid.

\section{UCAPAN TERIMA KASIH}

Penulis mengucapkan terima kasih yang sebesar-besarnya kepada semua pihak yang membantu dan terlibat dalam penelitian ini, terutama Institut Kesehatan Helvetia Medan dan kepada Desa Lau Mulgab yang telah memberikan izin dan membantu jalannya penelitian ini.

\section{DAFTAR PUSTAKA}

1. Kusmiran E. Kesehatan reproduksi remaja dan wanita. Jakarta Salemba Med.
2011;21.

2. Khoerunisya DA. Hubungan Regulasi Emosi dengan Rasa Nyeri Haid (Dismenore) pada Remaja. Published online 2015.

3. Heni Setyowati ER, Kp S, Kes M. Akupresur Untuk Kesehatan Wanita Berbasis Hasil Penelitian. Unimma Press; 2018.

4. Sari W, Kes M, Indrawati L, Kes M, Basuki Dwi Harjanto MM. Panduan Lengkap Kesehatan Wanita. Penebar PLUS+; 2012.

5. Lestari NMSD. Pengaruh dismenorea pada remaja. In: Prosiding Seminar Nasional MIPA. ; 2013.

6. Novarenta A. Guided imagery untuk mengurangi rasa nyeri saat menstruasi. $J$ Ilm Psikol Terap. 2013;1(2):179-190.

7. Wulandari E, Hadisaputro S, Runjati R. Pengaruh Abdominal Stretching Exercise Terhadap Penurunan Kadar Prostaglandin Pada Dismenore Primer. Published online 2016.

8. Yohana SK, Fathunikmah F. Hubungan Teknik Relaksasi Pernafasan Terhadap Intensitas Nyeri Persalinan Kala I Fase Aktif Pada Ibu Bersalin Normal Di Klinik Pratama Jambu Mawar Dan Klinik Pratama Afiyah Pekanbaru Tahun 2017. J IBU DAN ANAK. 2017;5(1):9-15.

9. Lisna Hidayati. Telang "Si Biru" Anti Stres.

https://bioprospek.biologi.ugm.ac.id/2018 /10/16/telang-si-biru-anti-stres/.

10. Geofani Dio Prasasti. Berbagai Manfaat Ini Buktikan Teh Biru Tak Kalah dari yang Hijau. Published online 2018.

11. Siti Yulianingsih. Kembang Telang, Si Biru Nan Cantik Yang Memiliki 8 Manfaat Bagi Kesehatanmu.

12. Rohyanti F. Pengaruh Teknik Relaksasi Lamaze Terhadap Tingkat Nyeri Persalinan Kala I Fase Laten pada Ibu Intranatal di RSUD Wates Kulonprogo. Published online 2011. 
13. Rahmawati VY. Pengaruh Lamaze Exercise Terhadap Skala Nyeri Menstruasi (Dysmenorrhoea) Pada Remaja Putri Di Sma Budi Mulia Jakarta. J Ilmu Kesehat Kosala. 2017;5(1).

14. Kerthyasa TG. Sehat Holistik Secara Alami. Qanita; 2013. 